\title{
Definitive human and mouse hematopoiesis originates from the embryonic endothelium: a new class of HSCs based on VE-cadherin expression
}

\author{
ESTELLE OBERLIN*,1,2, BOUCHRA EL HAFNY1,2,\#, LAURENCE PETIT-COCAULT11,2 and MICHĖLE SOUYRI*,1,2 \\ ${ }^{1}$ Inserm, U602, Villejuif and ${ }^{2}$ Université Paris-Sud, Institut André Lwoff, Villejuif, France
}

\begin{abstract}
Hematopoietic stem cells (HSCs) arise first in the third week of human ontogeny inside yolk sac developing blood vessels, and independently, from the wall of the embryonic aorta and vitelline arteries one week later. HSCs produced in the yolk sac and in the embryonic truncal arteries migrate to and transiently colonize the embryonic liver (EL), and thereafter the bone marrow (BM), their permanent site of residence. At the moment, the origin of human HSCs is still controversial; one of the main hypotheses being that they are generated by hemogenic endothelial cells (ECs). To proove definitively the endothelial origin of HSCs that arise within the human embryo, we previously purified ECs from either the yolk sac or the truncal arteries and reported that they were able to produce blood cells in vitro. We then found that some of the HSCs present in the human EL were co-expressing vascular endothelial (VE)-cadherin, an endothelial marker, CD45, a pan-hematopoietic marker, and CD34, a common endothelial and hematopoietic marker, and demonstrated that these HSCs bearing a dual hemato-endothelial phenotype were endowed with remarkably high self renewal and proliferative potentials. Furthermore, a transgenic mouse model based on the VE-cadherin cis-regulating elements that we engineered to trace the fate of the first VE-cadherin expressing cells allowed us to clearly demonstrate that a majority of adult BM HSCs derived from a VE-cadherin ancestor. Altogether our studies strongly suggest that at least a part of both the human and the murine hematopoietic systems arise from an endotheliumlike ancestor.
\end{abstract}

KEY WORDS: human, embryo, hematopoietic stem cell, hemogenic endothelium, VE-cadherin

\section{Introduction}

Blood cells are constantly produced in the bone marrow (BM) of adult mammals. This turnover depends on a rare population of cells that display self-renewal and multilineage differentiation potential, the hematopoietic stem cells (HSCs). It is generally accepted that HSCs are generated during embryonic development to sequentially colonize the embryonic liver (EL) and finally the BM. Identifying the embryonic sites from which the adult pool of HSCs originates is crucial for understanding the mechanisms responsible for the generation of adult stem cells. Because HSCs always emerge in close physical association with endothelial cells (ECs), a common origin for the two cell types has been proposed (reviewed in Dzierzak and Speck, 2008; Cumano and Godin, 2007). In the human embryo, the first hematopoietic cells (HCs) are produced in the yolk sac, from about 16 days of development (Luckett, 1978). HCs and ECs simultaneously differentiate within blood islands, leading to joint formation of both blood and blood vessels. This close physical association between the first HCs and ECs was long suggested as relying on a common mesodermal cell ancestor designated as the hemangioblast (Sabin 1920; Murray 1932). It was originally hypothesized that the yolk sac was the sole provider of HSCs giving rise to cells that were going to colonize the $\mathrm{EL}$ and the BM. In the last quarter of the $20^{\text {th }}$ century, this prevailing view was challenged by the demonstration of HSC

\footnotetext{
Abbreviations used in this paper: BM, bone marrow; EL, embryonic liver; HSC, hematopoietic stem cell; LTR, long-term reconstitution; VE, vascular endothelial; VECR, double transgenic VE-cadherin-Cre/Rosa26R mouse.
}

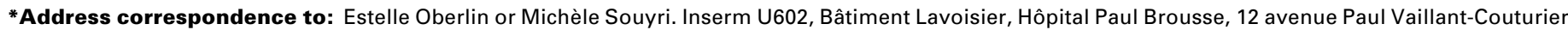
94807 Villejuif cedex, France. Fax: +33-1-4559-5268. e-mails: estelle.oberlin@inserm.fr or michele.souyri@inserm.fr

\# Present address: CNRS UPR4301 Orléans, France
}

Final author corrected PDF published online: 16 July 2010.

ISSN: Online 1696-3547, Print 0214-6282

(c) 2010 UBC Press

Printed in Spain 
production in the embryo proper, first documented in bird (reviewed in Dieterlen-Lièvre, 1994), then in mouse (reviewed in Dzierzak and Speck 2008; Mikkola and Orkin, 2006) and human (reviewed in Peault et al., 2002). Even more obvious than in the yolk sac, intraembryonic HSCs were noted to arise in close physical association with the ventral endothelium of the dorsal aorta. In the human embryo, these cells were first detected at day 27 , in the aortic endothelium as well as in the umbilical and vitelline arteries surface. They then expand rapidly to form clusters of several thousand cells at day 35 and disappear at day 40 (Tavian et al., 1996 and 1999). These observations led to the proposal that $\mathrm{ECs}$ may give rise to $\mathrm{HCs}$. Direct filiation of $\mathrm{HCs}$ from pre-existing endothelium was suggested by using lineage-marking experiments of ECs in the avian embryos (Jaffredo et al., 1998 and 2000). In the mouse, candidate ECs sorted from the yolk sac and embryonic aorta-gonad-mesonephros (AGM) region formed blood cells in culture (Nishikawa et al., 1998b, Fraser et al., 2002). Recently, several lineage-marking systems have been developed to directly approach the question of the temporal and spatial origin of blood cells in situ (Chen et al., 2009; Zovein et al., 2008; Li et al., 2006; De Bruijn et al., 2002; North et al., 2002). All these approaches have suggested that discrete subsets of vascular ECs transiently exhibit blood-forming potential during vertebrate development. Recently a novel perspective to HSCs development came with the discovery that the human and murine placenta harbor a large pool of multipotential hematopoietic progenitors and stem cells, indicating that the placenta could play an important role in the establishment of hematopoiesis (Barcena et al., 2009; Robin et al., 2009; Mikkola et al., 2005; see also Ottersbach and Dzierzak; Mikkola, Dieterlen-Lièvre et al., in this issue). This process of HSCs emergence in the placenta is also intimately associated with large vessels (Rhodes et al., 2008) and therefore do highlight the role of vascular ECs in the generation of HSCs in vertebrates not only in the AGM, the umbilical and vitelline arteries but also in the placenta. Several reports suggest that intaembryonic HSCs are generated by other structures, called subaortic patches (SAPs), located below the aortic floor, and which appear as another supportive niche for the intraembryonic HSCs generation in the paraaortic splanchnopleura (PSp)/AGM region (Bertrand et al., 2005; Manaia et al., 2000). At the end, it is possible that both origins exist (Zovein et al., 2008), and that depending on the site of production, HSCs might be endowed with different properties in adult life.

\section{Primitive and definitive human hematopoiesis origi- nate from the embryonic endothelium}

To address whether vascular ECs in the human yolk sac, AGM, EL and fetal BM are endowed with hematopoietic ability, we sorted endothelial and hematopoietic progenitor cells from these blood-forming tissues and tested their hematopoietic potential in vitro. At these early stages of development, most surface markers expressed on $\mathrm{HCs}$ are also present on ECs, with the exception of CD45, a hematopoietic-specific marker. To discriminate between these two cell lineages, we sorted endothelial and hematopoietic progenitor cells on their common expression of CD34 and CD31, and absence of CD45 at the surface of ECs. When cultured in the presence of MS-5, a mouse BM stromal cell line that supports the multilineage, long-term development of human HSCs, the
CD34+CD31+CD45- embryonic and fetal ECs were able to produce blood cells. This was the case for ECs sorted from human yolk sac and AGM region but also, less expectedly, from EL and fetal BM (Oberlin etal., 2002). However the frequency of hemogenic ECs in the EL and fetal BM remained much lower than in the yolk sac and in the aorta region (Oberlin et al., 2002). Finally, it must be emphasized that no hematopoietic potential was ever detected among CD34 ${ }^{+} \mathrm{CD} 31^{+} \mathrm{CD} 45^{-}$sorted cells from non-hematopoietic tissues such as the heart, fetal aorta, pancreas, lung or umbilical cord (Oberlin et al., 2002). Taken together our results demonstrated the existence of a blood-forming vascular endothelium in the human embryo and fetus. This hemogenic endothelium appears to be a characteristic of early sites of HCs emergence such as yolk sac and embryonic aorta, and could be at the origin of both primitive and definitive hematopoiesis. Surprisingly presence of hemogenic ECs, albeit at a lower frequency, was also observed in the $\mathrm{EL}$ and the fetal BM, where no HCs are supposed to emerge intrinsically. The mouse liver rudiment does not support hematopoiesis when organ-cultured apart from the rest of the embryo, which led to assume that hepatic hematopoiesis originates from extrinsic circulating progenitors (Johnson and Moore, 1975). Similarly, using chicken embryo parabionts (Metcalf and Moore, 1971) and quail/chicken embryonic chimeras (Le Douarin et al., 1975), it was shown that medullary hematopoiesis occurred via blood-borne stem cells. Direct migration of beforehand-labelled fetal liver HCs to the BM was suggested (Clapp et al., 1995). Yet, these results cannot totally rule out the participation of the liver and BM endothelial compartment to hematopoietic production, nor do they exclude the possibility that the liver and BM rudiments are colonized by angio-hematopoietic or pluripotent mesodermal stem cells that may be ancestors of hemogenic ECs or by hemogenic ECs themselves. Another possibility is that hemogenic precursors contained within EL and fetal BM CD $34^{+} \mathrm{CD} 31^{+} \mathrm{CD} 45^{-}$ cell populations could strictly correspond to hematopoietic precursors, which is only possible if we admit that commitment to $\mathrm{HCs}$ arise before CD45 expression by these cells. Indeed, previous studies in human and murine ES models demonstrated that during hematopoietic development CD41 is expressed before CD45 (Eilken et al., 2009; Lancrin et al., 2009; Mikkola et al., 2003; Vodyanik et al., 2006). Then, despite the fact that they are CD45-, the CD34+CD $31^{+}$CD $45^{-}$cells that we assimilated as ECs could correspond to already committed HCs.

\section{Hemogenic endothelium in the human embryo is de- rived from an earlier subaortic mesenchymal popula- tion}

We addressed the question of the origin of hemogenic ECs in the human embryo. Semi-thin sections through the aorta at hematopoietic stages revealed that ECs are profoundly disorganized, or even not present underneath intraaortic hematopoietic cell clusters (Tavian et al., 1999). This indicates a possible circulation between cells lining the aorta and those underneath, and that cluster-forming cells could originate from the mesenchyme underlying the aorta. Indeed aortic hemogenic ECs may derive from angio-hematopoietic or even pluripotent mesodermal progenitors that could migrate secondarily from the underlying mesoderm to the endothelium which lines the vessel and forms an 
interface between blood and the rest of the embryo. In agreement with this assumption, we showed that $\mathrm{CD} 34^{+} \mathrm{CD} 31^{+} \mathrm{CD} 45^{-}$ ECs isolated in the aortic region between day 23 to 26 did not display any hematopoietic potential, and that the earliest signs of aortic hematopoiesis were detected from day 27 (Oberlin et al., 2002). Conversely similar experiments performed on the PSp/ AGM of the pre-27-day embryo have demonstrated that the blood-forming activity was confined within non-endothelial, CD34CD31-CD45- cells (Zambidis et al., 2006). This indicates that blood-forming potential is not imprinted in AGM ECs but is rather acquired upon colonization of the ventral wall of the aorta by a population of angiohematopoietic or pluripotent stem cells shortly before the $27^{\text {th }}$ day of development (rewiewed by Tavian et al. in this issue). These progenitors, already present in the PSp during the third week of development could be at the origin of hemogenic ECs which in turn could give rise to aortic HSCs. Interestingly, we were not able to detect a blood-forming activity within non-endothelial, CD34-CD31-CD45- cells sorted from the embryonic aorta in the post-27-day embryo, when HSCs have already emerged in the AGM region (Oberlin et al., unpublished observations), which indicates that later subaortic mesenchymal cells fail to produce $\mathrm{HCs}$ in vitro. Thus, only the early and transient PSp/AGM mesenchymal population that gives rise to AGM aortic hemogenic endothelium has the capacity
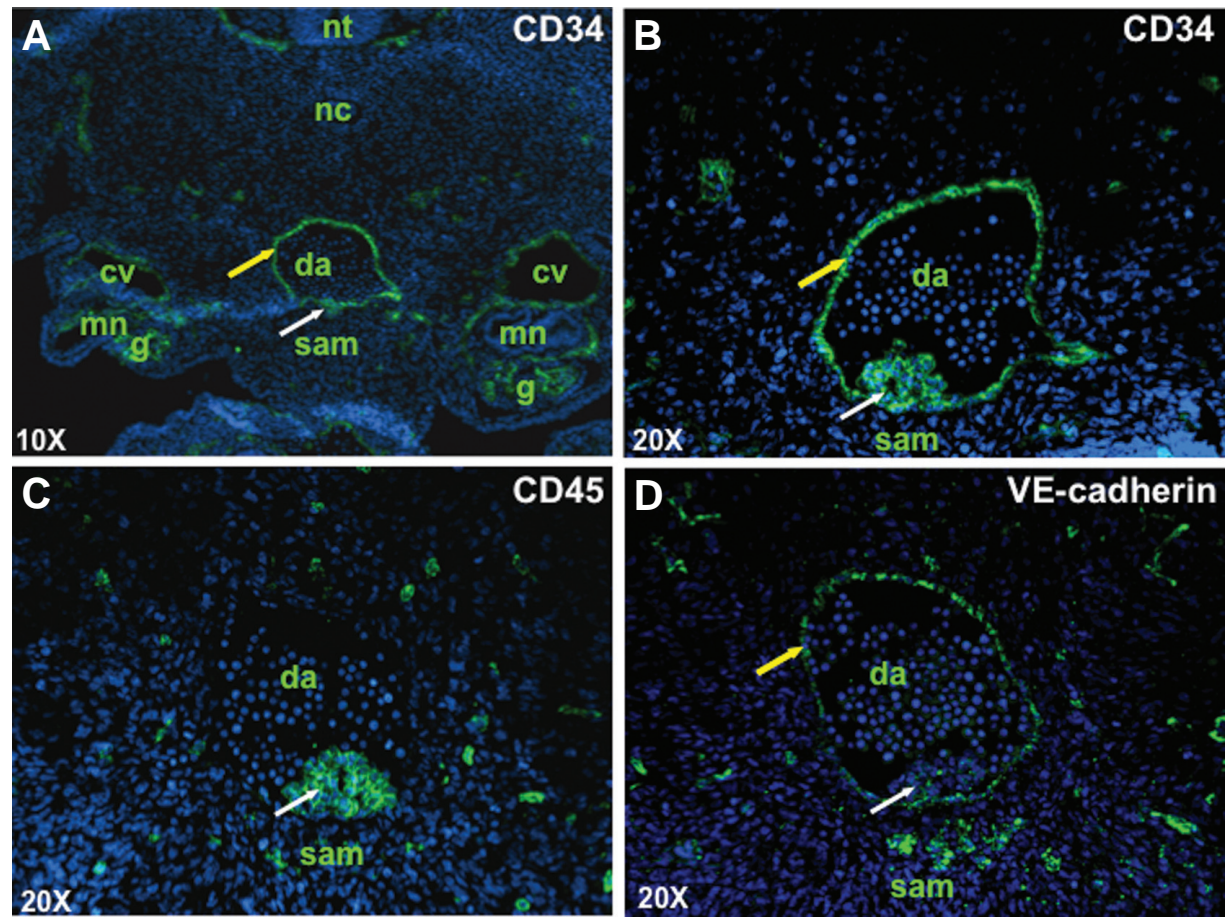

Fig. 1. Immunolocalization of endothelial and hematopoietic cells in the aorta region of the human embryo. Cross-section through the dorsal aorta (Ao) in a 5-week-old human embryo immunostained with CD34 (A,B), CD45 (C) and VE-cadherin (D). (A,B) CD34 is expressed on both endothelial (yellow arrow) and adherent intraaortic hematopoietic (white arrow) cells. (C) CD45 is expressed on adherent intraaortic hematopoietic cells (white arrow) and absent from the vascular endothelium. (D) VE-cadherin is expressed on aortic endothelial cells (yellow arrow), but also on hematopoietic cells clumped on the vessel floor (white arrow). VE-cadherin also recognizes cells in the mesenchyme underneath aorta. Sections were observed with a Nikon Eclipse E800 microscope equipped with Optigrid for confocal acquisition. Images were processed using Photoshop 7.0 software (Adobe Systems, San Jose, CA). Abbreviations: nt, neural tube; nc, notochord; g, gonad; mn, mesonephros; da, dorsal aorta; sam, subaortic mesenchyme.

to produce HSCs progeny, and appears to do so through an endothelial intermediate. This results correlates with recent studies of aortic floor formation in both avian and murine systems (Wiegreffe et al., 2009 and 2007; Pouget et al., 2008 and 2006; Wasteson et al., 2008; see also Jaffredo et al., this issue) showing that the mesenchymal floor of the AGM region is transiently formed by a population derived from the lateral plate mesoderm and capable of contribution to the aortic endothelium, then replaced by a second population derived from sclerotomal mesoderm, that migrates from the dorsal and lateral walls to the ventral side of the aorta.

\section{Seeking for the endothelial to hematopoietic cell tran- sition in the human embryonic aorta}

We reported above that angio-hematopoietic or pluripotent mesodermal stem cells, already present in the PSp during the third week of development could be at the origin of hemogenic ECs which could in turn give rise to aortic HSCs. In order to better elucidate the transition between the hemogenic endothelium and the hematopoietic clusters we performed immuno-histological localization of ECs and HCs in the human AGM region with CD45, CD34 and VE-cadherin, a specific marker for ECs (Lampugnani et al., 1992). Immuno-histochemistry on a 5-week-old human embryo confirmed that all vascular ECs lining the dorsal aorta express CD34 (Fig. 1 A,B) while CD45 expression was restricted to $\mathrm{HCs}$ disseminated in very low numbers within tissues, albeit somehow more densely in the subaortic mesenchyme (Fig. 1C). None of these HCs scattered throughout embryonic tissues was ever found positive for CD34 expression (Fig. 1A and 1B). CD45 ${ }^{+}$ cells were very rarely detected inside blood vessels, which contained almost exclusively erythrocytes (Fig. 1C). In contrast, HCs clustered on the ventral endothelium of aorta were all CD34 ${ }^{+} \mathrm{CD} 45^{+}$ (Fig. 1A, 1B and 1C), as documented before (Oberlin et al., 2002; Tavian et al., 1999 and 1996). As expected, the VE-cadherin adhesion molecule was present at the luminal aspect of vascular endothelium, but also on HCs clumped on the vessel floor, yet to a lesser extend (Fig. 1D). This immuno-localization confirmed that all vascular ECs in the human embryo express CD34 and VEcadherin and can be readily distinguished from hematopoietic progenitors by the absence of CD45 expression. Immuno-labellings also show for the first time that HCs present in the human embryonic aorta are co-expressing the endothelial specific marker VE-cadherin and the pan-leukocyte antigen CD45. This is in agreement with studies in the mouse embryo showing that HSCs that appear in the YS and the AGM are bearing such a dual 
hemato-endothelial phenotype (Taoudi et al., 2005 and 2008; Fraser et al., 2003; North et al., 2002). Thus, as in the mouse embryo, the first founder HSCs of human embryo seem to maintain endothelial feature while acquiring hematopoietic traits, which confirms that definitive hematopoiesis originates from the embryonic endothelium.

\section{Progressive divergence of definitive hematopoietic stem cells from the endothelial compartment in the human embryonic liver}

Since HCs produced in the embryonic aorta are likely to seed the EL we hypothesized that cells expressing both endothelial and hematopoietic traits could also be detected in the human EL, as it has already be demonstrated in the mouse fetal liver (Kim et al., 2005; Taoudi et al., 2005). As expected, we found that some of $\mathrm{HCs}$ present in the EL co-expressed the pan-leukocyte antigen CD45 and the endothelial specific marker VE-cadherin (Fig. 2). Indeed, VE-cadherin and CD45 expressions were predominantly mutually exclusive except in a very rare double-positive (DP) cell population constituting less than $0.5 \%$ of the total liver population (Fig. 2). We also observed that this population decreased throughout EL development and was completely lost at the fetal liver stage, suggesting that as hematopoietic development progresses VE-cadherin was downregulated, and that the DP cells could give rise to VE-cadherin- HCs (Oberlin et al., submitted). Extensive flow cytometry analysis, used to better characterize the DP VEcadherin ${ }^{+} C D 45^{+}$cell subset, revealed significant differences between the DP and the EC fractions (Table 1). Whereas ECs strongly expressed endothelial markers, the DP cells did not, or expressed them only on few cells. As expected, the HC fraction was either negative for these markers, or expressed them on a very low number of cells (Table 1). Conversely, analysis of HSC specific cell-surface markers demonstrated that the majority of the DP cells expressed these markers, whereas only few cells of the HC population did (Table 1). Flow cytometry analysis also revealed that the DP fraction had a cell surface phenotype that included the expression of early hematopoietic differentiation markers (Table 1). Another phenotypic feature of the DP population was the absence of cell-surface markers associated with hematopoietic lineage differentiation (Oberlin et al., submitted). Thus our phenotypic analysis reveals higher similarity between DP cells and HCs than between DP cells and ECs, and strongly suggests that if the DP cell population is an intermediary population between the endothelial and the hematopoietic populations, it seems to have already diverged from the endothelial compartment and to be committed to the hematopoietic compartment. To determine precisely which type of $\mathrm{HCs}$ (hematopoietic progenitors or stem cells) is contained in the DP population, we sorted a subpopulation of 34DP cells, co-expressing VE-cadherin, CD45 and CD34 (the majority of the DP cells expresses CD34 - see Table 1) from the EL, and evaluated its hematopoietic potential in vitro and in vivo. In all cases, this potential was compared to that of the subpopulation of 34HCs expressing CD45 and CD34 but lacking VE-cadherin. Hematopoietic assays clearly demonstrated functional differences between the two cell populations. First, all the colonies produced by 34DP cells in colony-forming cells assays were typical high proliferation potential (HPP)-colony-

\section{Immunophenotyping and cell sorting}

Fig. 2. Phenotypic and functional analysis of human embryonic liver VEcadherin ${ }^{+} \mathrm{CD}^{-} 5^{-}$(endothelial), VE-cadherin-CD45+ (hematopoietic) and VEcadherin+CD45+ (double positive) cell populations: experimental model. Human embryonic livers ranging from 6 to 23 weeks of gestation were dissociated by enzymatic disruption and whole liver cells were doublestained with anti-human CD45-FITC and VE-cadherin$P E$ monoclonal antibodies. Flow cytometric analysis of a representative 7,5-day old human embryonic liver is shown, demonstrating VEcadherin+ ${ }^{+}$C45- endothelial, $V E$-cadherin- $\mathrm{CD}^{4} 5^{+}$hematopoietic and VEcadherin+CD45+ DP cell
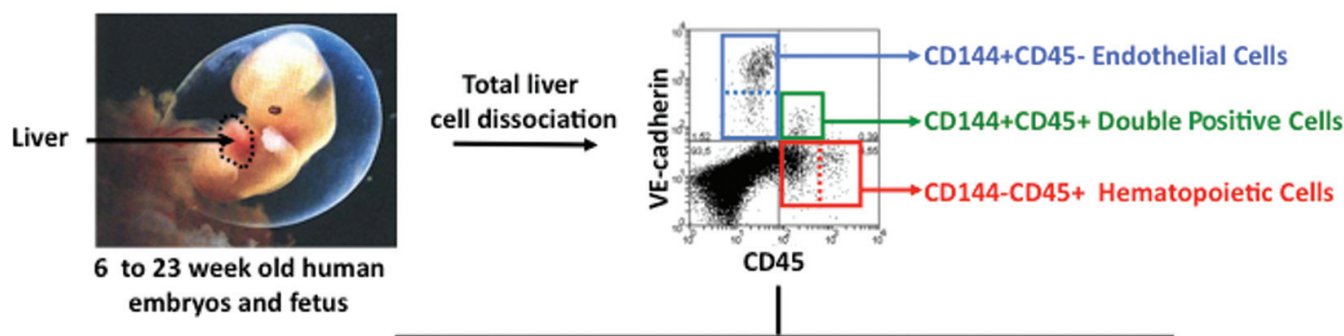

In VIVO hematopoietic assays
In VITRO hematopoietic assays

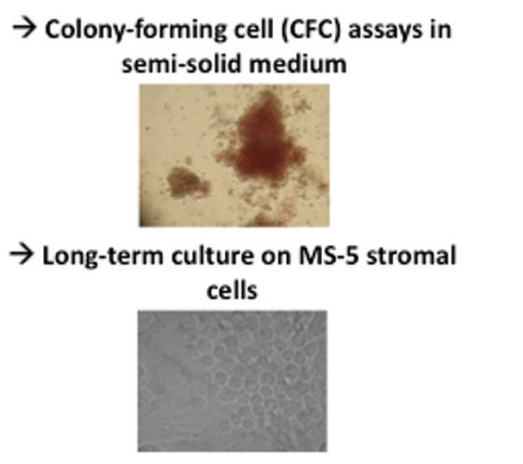

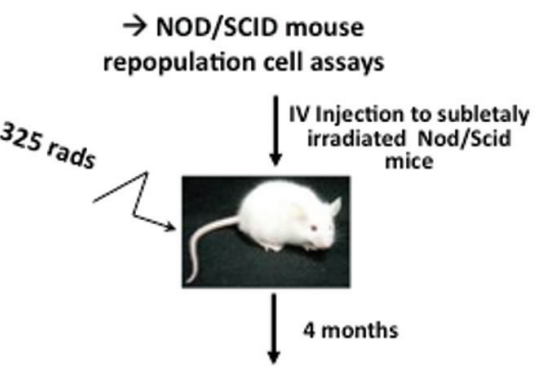

BM analysis for the presence of human

populations. We could identify VE-cadherin+CD45- endothelial cells (blue box) expressing high and low level of VE-cadherin, while double positive VEcadherin ${ }^{+} C D 45^{+}$cells only express low level of VE-cadherin (green box). Similarly, VE-cadherin-CD45+ hematopoietic cells expressed high and low level of CD45 (red box) while VECAD+CD45+ (green box) cells only express low level of CD45. Endothelial, hematopoietic and double positive cell populations were either submitted to flow cytometry analysis or functionally analyzed, using in vitro or in vivo hematopoietic assays. 
forming units (CFUs) while no HPP-CFUs were produced by the $34 \mathrm{HC}$ population (Fig. 3A). Likewise, only 34DP cells were able to produce secondary hematopoietic colonies. Second, the kinetic of proliferation in long-term culture assays were obviously distinct in the two populations. 34DP cells produced $\mathrm{HCs}$ with a delay compared to the $34 \mathrm{HCs}$ (Fig. 3B) and extended long-term hematopoiesis only occurred in wells seeded with the 34DP population. Third, the repopulating ability of the 34DP cells in NOD/ SCID mice was much better than that of the $34 \mathrm{HCs}$, since all transplanted mice were reconstituted when as few as 5000 34DP cells were transplanted, whereas no mice were reconstituted with $500034 \mathrm{HCs}$. Even when ten times more 34HCs were transplanted, only one mouse out of 6 was reconstituted, testifying the high reconstitution potential of the 34DP cells (Oberlin et al., submitted). We also tested the hematopoietic capacities of the EC fraction and confirmed that EL ECs were no longer, or weakly capable of producing $\mathrm{HCs}$ in vitro and in vivo (Oberlin et al., submitted). Thus, our in vitro hematopoietic cell assay and in vivo long-term transplantation experiments in NOD/SCID mice demonstrated that in EL hematopoietic differentiation was more or less exclusively associated with the 34DP and 34 HC fractions, and that the 34DP population was endowed with higher self renewal, proliferative and reconstitution potentials than its $34 \mathrm{HC}$ counterpart. Thus 34DP cells could be enriched for primitive hematopoietic progenitors and stem cells compared to $34 \mathrm{HCs}$, and could represent an earlier stage of development. The more primitive 34DP population could represent an intermediary population

TABLE 1

RELATIVE EXPRESSION OF ENDOTHELIAL AND HEMATOPOIETIC CELL SURFACE ANTIGENS BY EC, HC AND DP HUMAN EMBRYONIC LIVER CELL POPULATIONS

\begin{tabular}{|c|c|c|c|c|c|}
\hline \multirow[b]{3}{*}{ Markers } & \multicolumn{5}{|c|}{ Percent markers expression } \\
\hline & $\begin{array}{l}\text { VECAD }^{\text {high }} \\
\text { CD45 }^{-}\end{array}$ & $\begin{array}{l}\text { VECAD }^{\text {low }} \\
\text { CD45 }^{-}\end{array}$ & $\begin{array}{l}\text { VECAD low } \\
\text { CD45 low }\end{array}$ & $\begin{array}{l}\text { VECAD } \\
\text { CD45 }^{\text {low }}\end{array}$ & $\begin{array}{l}\text { VECAD' } \\
\text { CD45 }^{\text {high }}\end{array}$ \\
\hline & ECs & ECs & DP cells & HCs & HCs \\
\hline \multicolumn{6}{|c|}{ Endothelial Markers } \\
\hline KDR & 85,5 & 68,4 & 5,3 & 0,5 & 2,8 \\
\hline CD146 & 97,8 & 89 & 0 & 0,2 & 3,5 \\
\hline UEA-1 receptor & 98,1 & 92,3 & 11,1 & 0,5 & 0,6 \\
\hline TIE-2 & 72 & 22,4 & 25,2 & 2,3 & 0,6 \\
\hline CD31 & 98,6 & 91,8 & 99,1 & 88,8 & 75,8 \\
\hline \multicolumn{6}{|l|}{ HSC Markers } \\
\hline CD34 & 99,6 & 92,8 & 93,7 & 45,6 & 3,81 \\
\hline AC133 & 0,06 & 0,4 & 22,5 & 4,19 & 0 \\
\hline CD38 & 0 & 0 & 11,3 & 29,8 & 89,9 \\
\hline HLA-DR & 0 & 0 & 41,1 & 16,7 & 22,8 \\
\hline CD90 & 22 & 24,3 & 21 & 0,7 & 0,2 \\
\hline \multicolumn{6}{|c|}{ Early Hematopoietic Markers } \\
\hline CD41 & 6,7 & 5,2 & 36,3 & 14 & 0,7 \\
\hline CD49d & 3,3 & 15 & 78,3 & 92,3 & 69,4 \\
\hline CD43 & 0 & 0 & 60,9 & 79,8 & 61,8 \\
\hline CD44 & 0 & 8,63 & 84 & 72,9 & 94 \\
\hline
\end{tabular}

Endothelial (EC) populations: VE-cadherin ${ }^{\text {high }} \mathrm{CD} 45^{-}$and VE-cadherin ${ }^{\text {low }} \mathrm{CD} 45$ Hematopoietic (HC) populations: VE-cadherin-CD45 low and VE-cadherin-CD45 high Double-positive (DP) populations: VE-cadherin low $C D 45^{\text {low }}$

Six- to 9-week-old human embryonic livers were dissociated and whole liver cells were triplestained with CD45-FITC, VE-cadherin-PE and either an endothelial specific or a hematopoietic specific-APC monoclonal antibody, and analysed by flow cytometry. Analysis of DP, endothelia and hematopoietic populations was performed on 100,000 whole embryonic liver cells. All data are representative of at least three experiments. between the hemogenic ECs that we previously identified in the human embryo and fetus, and the more advanced $34 \mathrm{HC}$ population. The 34DP population could diverge from hemogenic ECs prior to the onset of definitive hematopoiesis, loosing endothelial markers expression as they gain hematopoietic markers expression.

\section{Fate mapping of endothelial cells during mouse development: VE-cadherin to trace the origin of hematopoietic cells}

Unravelling the origins of early hematopoiesis through analysis of human embryos and fetus is difficult, both practically and ethically. Although such studies have yielded valuable information (Zambidis et al., 2006) most data on ontogeny of vertebrate blood formation have been gained through analysis of model organisms including mice. To prove the endothelial origin of murine HSCs few groups engineered transgenic mice to trace the ECs descent, taking advantage of the Cre/lox system. This model requires two transgenic lines: one with $\mathrm{CRE}$ recombinase under the control of the promoter of a gene of interest (gene specific for endothelial lineage, for instance), and a second line that contains a conditional reporter gene (lacZ or GFP), "floxed" (ie expression
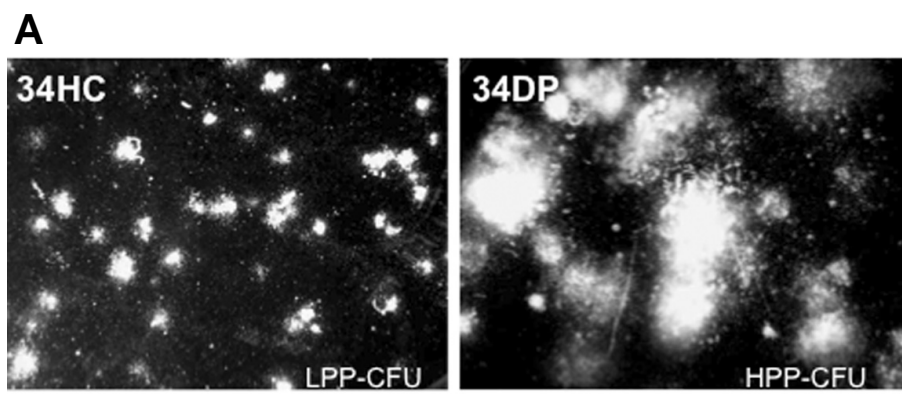

B
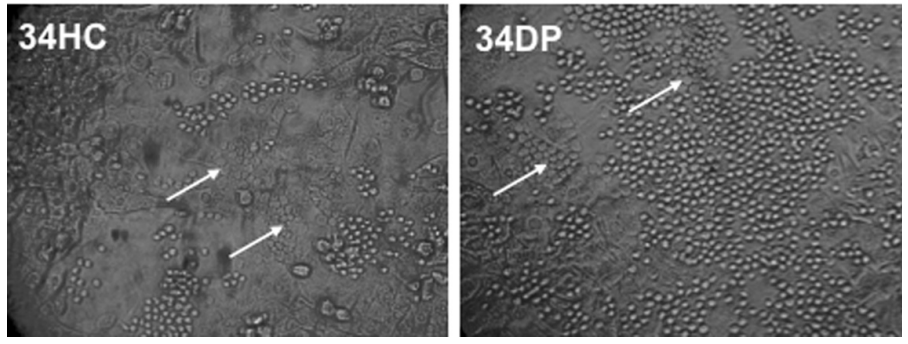

Fig. 3. In vitro generation of hematopoietic cells from 34 doublepositive (DP) and 34 hematopoietic (HC) human embryonic liver cells. 34DP cells and 34HCs sorted from a 8-week-old embryonic liver were either plated in methylcellulose medium (Methocult GF H4434 kit; Stem Cell Technologies, Grenoble, France) according to the manufacturer's instructions (panel A; magnification: 3X, or grown on MS-5 stromal cells (panel B; magnification: 200X. Photographs show typical HPP-CFUs and LPP-CFUs obtained after 14 days of culture (A) and typical hematopoietic colonies obtained after 21 days of culture (B), for 34DP cells and 34HCs respectively. During hematopoietic cultures, 34DP cells and $34 \mathrm{HCs}$ gave rise to colonies of packed round hematopoietic cells on MS-5 cells and to colonies of cobblestone shaped hematopoietic cells underneath the stroma (white arrows). Such hematopoietic colonies were observed from day 3 up to day 60 of culture for 34 HCs and from day 7 up to day 120 of culture for 34DP cells. 
of reporter gene is dependent on the excision of a stuffer sequence flanked by two lox sequences), under the control of an ubiquitous promoter. Classically, the Rosa26R reporter mouse line established by Soriano (Soriano, 1999) (reporter gene = lacZ or GFP or YFP) is used. In the double transgenic mice, the first cells which express the gene of interest will be permanently labelled with the reporter gene, and this will allow following their filiations.

All the models recently developed used the promoter element of the VE-cadherin gene (CD144 or cadherin 5), a specific marker for adult ECs, which is essential for endothelial cell-cell interaction (Dejana, 2004). VE-cadherin is required in vivo in the postnatal vasculature to maintain ECs integrity and barrier function (Corada etal., 1999). Absence of VE-cadherin by homologous recombination leads to embryonic lethality by day E9.5 due to severe vasculogenic defects in the yolk sac and embryo (Carmeliet et al., 1999; Gory-Faure et al., 1999). Using in vitro differentiation of murine ES cells, Nishikawa et al. showed that FLK1+VE-cad ${ }^{+}$CD45- cells represent a population at the diverging point of hematopoietic and endothelial cell lineages (Nishikawa et al., 1998a). The same team demonstrated that VE-cad ${ }^{+}$CD45- ECs isolated from E9.5 embryos and yolk sac are able to generate HCs in vitro(Nishikawa etal., 1998b, Fraser et al., 2003). VE-cadherin is also expressed by HSCs emerging in hematopoietic sites (AGM E11.5 and YS E12.5) (Taoudi et al., 2005 and 2008; Fraser et al., 2003; North etal., 2002). This expression disappears after liver colonization (Kim et al., 2005; Taoudi et al., 2005).

Three groups engineered a VE-cad CRE transgenic mouse, using the $2.5 \mathrm{~kb} 5$ ' promoter element of the VE-cadherin gene, described by Gory et al. (Gory et al., 1999) (Kogata et al., 2006; Alva et al., 2006; Zovein et al., 2008; Chen et al., 2009). In addition to the constitutive VE-cad/CRE transgene, M.Luisa Iruela-Arispe's team designed a conditional VE-cad/ CRE ER ${ }^{\mathrm{T} 2}$ transgenic mouse, allowing inducible recombination in the endothelium after tamoxifen injection (Monvoisin et al., 2006). Based on data from Hisatsune et al. (Hisatsune et al., 2005), our group designed another VE-cad transgenic mouse, with the Cre recombinase under the control of both the 5 , promoter flanking region and the 5' half of the first intron of VE-cadherin gene (Fig. 4A and Petit-Cocault et al., submitted): an enhancer region is present in this first intron, which augments the activity of the $2.5 \mathrm{kbp} \mathrm{5}$ ' promoter region while maintaining endothelial specificity. This combination is so far the most optimum for ECs-specific gene expression that can also express gene in VE-cad ${ }^{+}$progenitors of $\mathrm{HCs}$, but not in fully committed HCs (Hisatsune et al., 2005).

In all the models, mating with Rosa26R LacZ or GFP mice demonstrated that $\beta$-gal activity or GFP labelling could be detected throughout the vasculature in double transgenic VECR embryos, indicating that the VE-cadherin promoter was correctly activated in cells responsible for developmental vessel formation,
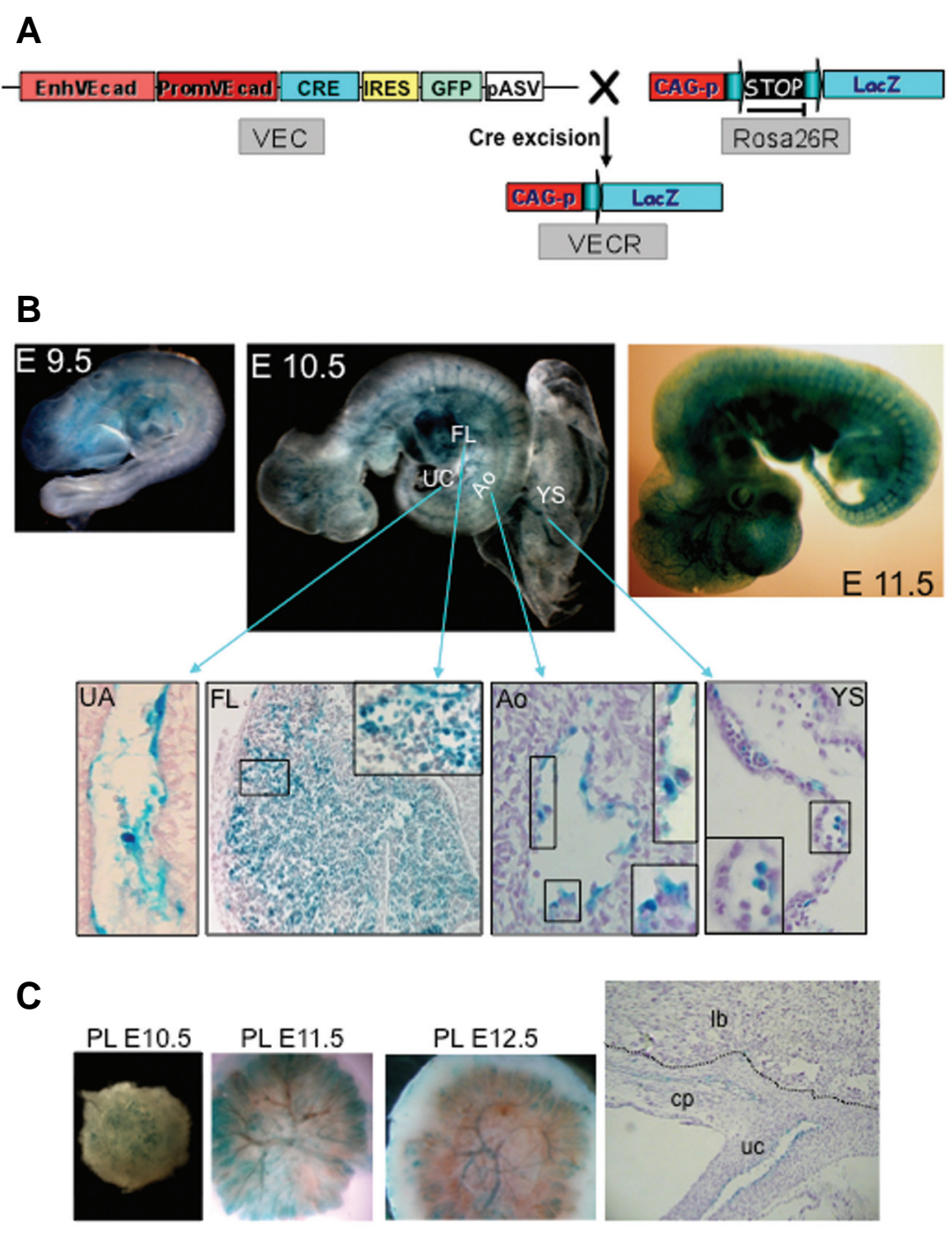

Fig. 4. Generation of the VEC mice and LacZ analysis of VECR embryos. (A) Schematic representation of the VE-cadherin promoter+enhancer driven Cre recombinase transgene (VEC), and of the obtention of the double transgenic VECR mice. (B) Whole-mount X-gal staining of E9.5, E10.5 and E11.5 VECR embryos shows progressive LacZ expression in intersomitic vessels, endocardium, as well as in the aorta (Ao), fetal liver (FL), yolk sac (YS) and umbilical (UA) and vitelline (not shown) arteries at E10.5. Down panel shows representative illustrations of $7.5 \mu \mathrm{M}$ cryosections of whole mounted E10.5 embryo and yolk sac, focused on UA, FL, Ao and YS respectively. Boxed areas are magnified. (C) Whole-mount X-gal staining of placenta at E10.5, 11.5, 12.5. 7.5 $\mu \mathrm{M}$ cryo-sections of E12.5 placenta showing that LacZ mainly labels the big vessels of the chorionic plate.

as expected. Of note, as soon as E10.5 we observed a large number of fetal liver cells with LacZ activity (Fig. 4B). At this stage, a high activity is also detected in the umbilical artery (Fig. 4B). In the placenta, at E11.5 and E12.5, when the highest number of HSCs can be detected (Mikkola et al., 2005), we found that LacZ activity resides mainly in the big vessels present in the chorionic plate rather than in the labyrinth (Fig. 4C). In addition, using the fluorescent substrate fluorescein-di- $\beta$-D-galactopyranoside (FDG) of $\beta$-gal, we could show that not only the VE-cadherin lineage labeled the AGM, yolk sac, placenta and fetal liver CD45+ hematopoietic populations, but also the $\mathrm{CD}_{3} 4^{+} \mathrm{c}-\mathrm{kit}^{\mathrm{hi}}$ population, enriched 
A

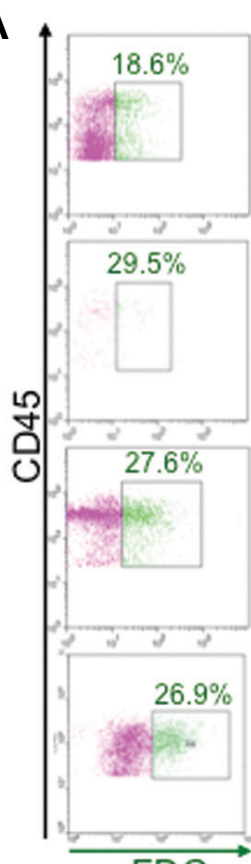

FDG

B

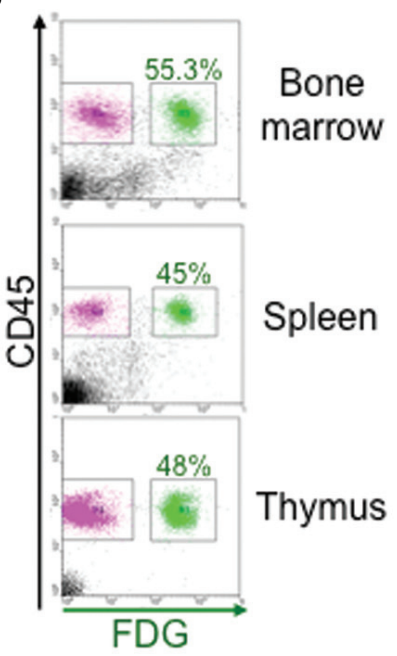

FL
AGM

PL

YS

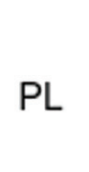

YS
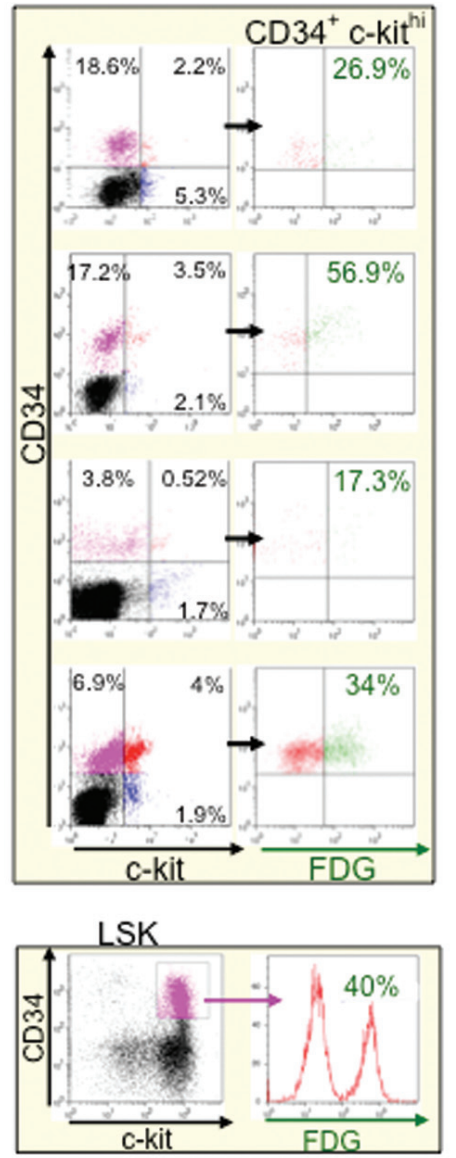

FDG
Primary reconstitution

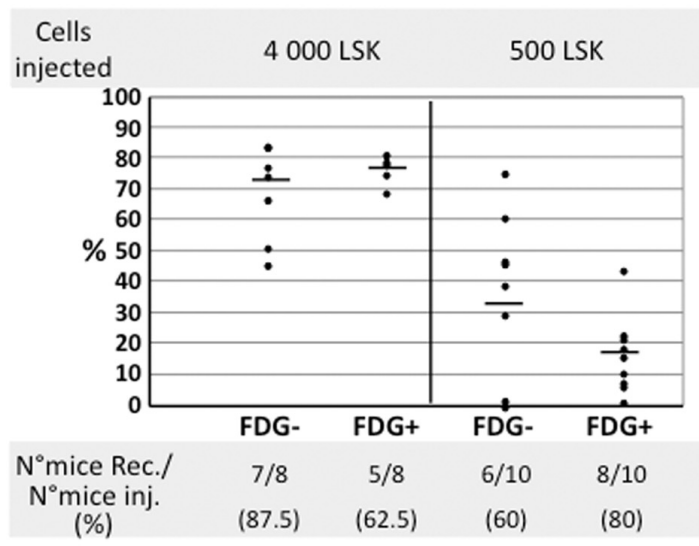

Secondary reconstitution

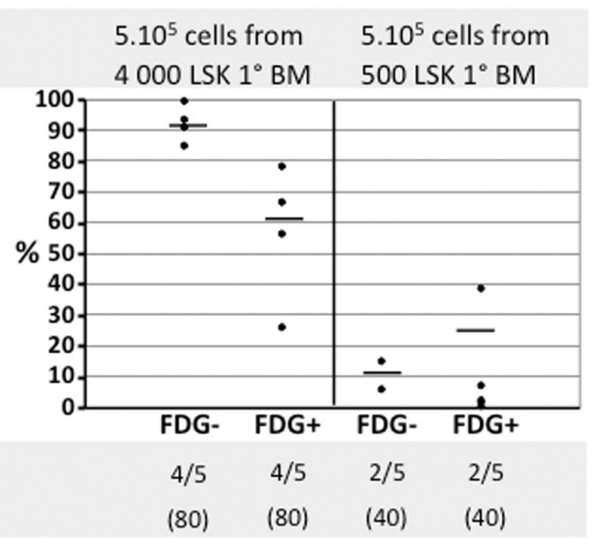

Fig. 5. VE-cadherin lineage labels HC and HSCs in hematopoietic sites of the embryo (A) and in adult bone marrow (B). (A) E10.5 AGM, Fetal Liver (FL), Placenta (PI), and Yolk Sac (YS) CD45+ HC and CD34+ C-

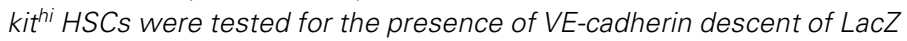
expressing cells by FACS analysis, using the fluorescent substrate fluorescein-di-P- $\beta$-galactopyranoside (FDG) of $\beta$-gal. One third of HCs and half of the AGM HSCs were already found to derive from a VE-cadherin expressing cell. (B) Half of adult HCs and LSK HSCs were found to be $F D G+$ and to originate from a VE-cadherin expressing ancestor.

in HSCs (Fig. 5A).

More variations were observed in adult mice: while Kogata et al. (Kogata et al., 2006) and Hisatsune et al. (Hisatsune et al., 2005) found that VE-cadherin promoter alone becomes less active after birth, as originally described by Gory et al. (Gory et al., 1999), and that a good expression in adults requires the enhancer element, Iruela-Arispe's (Alva et al., 2006) and Speck's (Chen et al., 2009) teams found a very good expression all over mice time life. Indeed, our transgenic model allowed a good expression in all the adult tissues that we analyzed (Petit-Cocault et al., submitted).

When double transgenic VECR mice were used to analyze the adult hematopoietic descent of VE-cadherin ECs, a majority of adult $\mathrm{HCs}$ were found to originate from a VE-cadherin expressing ancestor (20 to $90 \%$ of adult BM)(Fig. 5B). Moreover, using FDG, we showed that half of the lineage negative $\left(\mathrm{lin}^{-}\right) \mathrm{Sca}{ }^{+}{ }^{+} \mathrm{C}-\mathrm{kit}^{+}(\mathrm{LSK})$ HSC population of adult $\mathrm{BM}$ was $\mathrm{FDG}^{+}(38.1 \% \pm 5 \%$, range $30.4-$ $47.7 \%$ ), and therefore derived from a VE-cadherin ancestor (Fig. $5 \mathrm{~B})$. The FDG ${ }^{+} \mathrm{LSK}$ population presented the classical in vitro properties of HSCs with the same frequency of LTC-IC than FDG LSK cells $(0.0018 \pm 0.001$ versus $0.0020 \pm 0.001$, respectively). When injected in lethally irradiated Ly5.1 mice, FDG+LSK cells showed long-term hematopoietic reconstitution ability (Fig. 6), contributing to all lineages of BM, spleen, thymus and blood (PetitCocault et al., submitted). In addition, when BM cells from reconstituted animals were injected to secondary irradiated Ly5.1 recipients in order to test self-renewal ability, a significant number of Ly5.2+ ${ }^{+} \mathrm{FGG}^{+}$cells (10 to $61 \%$ ) were still detected in the BM of reconstituted mice more than 4 months after injection (Fig. 6). Our results strongly suggest that VE-cadherin embryonic endothelial population is at the origin not only of the majority of adult $\mathrm{HCs}$, but also of definitive BM resident HSCs. This conclusion is corroborated by the tamoxifen-inducible VE-cadherin Cre line developed 
by Zovein et al. (Zovein et al., 2008). Using a SMV $\alpha$ CRE and a myocardin CRE line which allowed them to trace mesenchyme separately, these authors further demonstrated that the endothelium is responsible for HSC emergence in the AGM and that it is derived from a transient mesenchymal population.

\section{Conclusion}

In conclusion, our observations confirm that at least part of emerging $\mathrm{HCs}$ in the human and murine embryos arise via an endothelium-like developmental intermediate. Our human studies clearly show that during human development, the hematopoietic potential seems to progressively shift from the endothelial to the hematopoietic compartment. Indeed, in the human EL, hematopoietic differentiation was associated more or less exclusively with the 34DP and 34HC fractions, whereas during earlier human embryo development such activity was also clearly associated with the endothelial fraction in the yolk sac and the AGM region. Furthermore, our mouse transgenic model clearly demonstrated that a majority, if not all of the adult BM HSCs are derived from a VEcadherin expressing ancestor. Thus both our human and murine approaches have unravelled a precise hematopoietic hierarchy and demonstrated that the two mammals display identical schemes concerning the development of their hematopoietic systems.

\section{Acknowledgements}

E.O. wishes to thank Dr. B. Peault for having initiating her to this work. We are grateful to Dr. Philippe Huber (INSERM U882) for providing us with the regulatory sequences of the VE-cadherin gene and to Maud Fleury for immunohistological analysis. This work was supported by grants from the ARC INCa and GEFLUC Associations.

\section{References}

ALVA, J.A., ZOVEIN, A.C., MONVOISIN, A., MURPHY, T., SALAZAR, A., HARVEY, N.L., CARMELIET, P., and IRUELA-ARISPE, M.L. (2006). VE-Cadherin-Crerecombinase transgenic mouse: a tool for lineage analysis and gene deletion in endothelial cells. Dev. Dyn. 235: 759-767.

BARCENA, A., KAPIDZIC, M., MUENCH, M.O., GORMLEY, M., SCOTT, M.A., WEIER, J.F., FERLATTE, C. and FISHER, S.J. (2009). The human placenta is a hematopoietic organ during the embryonic and fetal periods of development. Dev. Bio/327: 24-33.

BERTRAND, J.Y., GIROUX, S., GOLUB, R., KLAINE, M., JALIL, A., BOUCONTET, L., GODIN, I., and CUMANO, A. (2005). Characterization of purified intraembryonic hematopoietic stem cells as a tool to define their site of origin. Proc. Natl. Acad. Sci. USA 102: 134-139.

CARMELIET, P., LAMPUGNANI, M.G., MOONS, L., BREVIARIO, F., COMPERNOLLE, V., BONO, F., BALCONI, G., SPAGNUOLO, R., OOSTUYSE, B., DEWERCHIN, M., ZANETTI, A., ANGELLILO, A., MATTOT, V., NUYENS, D., LUTGENS, E., CLOTMAN, F., DE RUITER, M.C., GITTENBERGER-DE GROOT, A., POELMANN, R., LUPU, F., HERBERT, J.M., COLLEN, D., and DEJANA, E. (1999). Targeted deficiency or cytosolic truncation of the VEcadherin gene in mice impairs VEGF-mediated endothelial survival and angiogenesis. Cell 98: 147-157.

CHEN, M.J., YOKOMIZO, T., ZEIGLER, B.M., DZIERZAK, E., and SPECK, N.A. (2009). Runx 1 is required for the endothelial to haematopoietic cell transition but not thereafter. Nature 457: 887-891.

CLAPP, D. W., FREIE, B., LEE, W. H. AND ZHANG, Y. Y. (1995). Molecular evidence that in situ-transduced fetal liver hematopoietic stem/progenitor cells give rise to medullary hematopoiesis in adult rats. Blood 86: 2113-2122.

CORADA, M., MARIOTTI, M., THURSTON, G., SMITH, K., KUNKEL, R., BROCKHAUS, M., LAMPUGNANI, M.G., MARTIN-PADURA, I., STOPPACCIARO, A., RUCO, L., MCDONALD, D.M., WARD, P.A., and DEJANA,
E. (1999). Vascular endothelial-cadherin is an important determinant of microvascular integrity in vivo. Proc. Natt. Acad. Sci. USA 96: 9815-9820.

CUMANO, A. and GODIN, I. (2007). Ontogeny of the hematopoietic system. Annu. Rev. Immunol. 25: 745-785.

DE BRUIJN, M.F., MA, X., ROBIN, C., OTTERSBACH, K., SANCHEZ, M.J., and DZIERZAK, E. (2002). Hematopoietic stem cells localize to the endothelial cell layer in the midgestation mouse aorta. Immunity 16: 673-683.

DEJANA, E. (2004). Endothelial cell-cell junctions: happy together. Nat. Rev. Mol. Cell Biol. 5: 261-270.

DIETERLEN-LIĖVRE, F. (1994). Hemopoiesis during avian ontogeny. Poultry Sci. Rev. 5: 273-305.

DZIERZAK, E. and SPECK, N.A. (2008). Of lineage and legacy: the development of mammalian hematopoietic stem cells. Nat. Immunol. 9: 129-136.

EILKEN, H.M., NISHIKAWA, S. and SCHROEDER, T. (2009). Continuous singlecell imaging of blood generation from haemogenic endothelium. Nature 457: 896-900.

FRASER, S.T., OGAWA, M., YOKOMIZO, T., ITO, Y., NISHIKAWA, S., and NISHIKAWA, S. (2003). Putative intermediate precursor between hematogenic endothelial cells and blood cells in the developing embryo. Dev. Growth Differ. 45: 63-75.

FRASER, S.T., OGAWA M., YU R.T., NISHIKAWA S., YODER M.C., NISHIKAWA S. (2002). Definitive hematopoietic commitment within the embryonic vascular endothelial-cadherin(+) population. Exp. Hematol. 9: 1070-1078.

GORY, S., VERNET, M., LAURENT, M., DEJANA, E., DALMON, J., and HUBER, P. (1999). The vascular endothelial-cadherin promoter directs endothelialspecific expression in transgenic mice. Blood 93: 184-192.

GORY-FAURE, S., PRANDINI, M.H., POINTU, H., ROULLOT, V., PIGNOTPAINTRAND, I., VERNET, M., and HUBER, P. (1999). Role of vascular endothelial-cadherin in vascular morphogenesis. Development 126: 20932102.

HISATSUNE, H., MATSUMURA, K., OGAWA, M., UEMURA, A., KONDO, N., YAMASHITA, J.K., KATSUTA, H., NISHIKAWA, S., CHIBA, T., and NISHIKAWA, S. (2005). High level of endothelial cell-specific gene expression by a combination of the 5 ' flanking region and the 5 ' half of the first intron of the VE-cadherin gene. Blood 105: 4657-4663.

HOLTHOFER, H., VIRTANEN, I., KARINIEMI, A.L., HORMIA, M., LINDER, E., and MIETTINEN, A. (1982). Ulex europaeus I lectin as a marker for vascular endothelium in human tissues. Lab. Invest. 47: 60-66.

JAFFREDO, T., GAUTIER, R., BRAJEUL, V., and DIETERLEN-LIÈVRE, F. (2000). Tracing the progeny of the aortic hemangioblast in the avian embryo. Dev. Biol. 224: 204-214.

JAFFREDO, T., GAUTIER, R., EICHMANN, A., and DIETERLEN-LIEVRE, F. (1998). Intraaortic hemopoietic cells are derived from endothelial cells during ontogeny. Development 125: 4575-4583.

JOHNSON, G. R. and MOORE, M.A. (1975). Role of stem cell migration in initiation of mouse foetal liver haemopoiesis. Nature 258: 726-728.

KIM, I., YILMAZ, O.H. and MORRISON, S.J. (2005). CD144 (VE-cadherin) is transiently expressed by fetal liver hematopoietic stem cells. Blood 106: 903905.

KOGATA, N., ARAI, Y., PEARSON, J.T., HASHIMOTO, K., HIDAKA, K., KOYAMA, T., SOMEKAWA, S., NAKAOKA, Y., OGAWA, M., ADAMS, R.H., OKADA, M., and MOCHIZUKI, N. (2006). Cardiac ischemia activates vascular endothelial cadherin promoter in both preexisting vascular cells and bone marrow cells involved in neovascularization. Circ. Res. 98: 897-904.

LAMPUGNANI, M.G., RESNATI, M., RAITERI, M., PIGOTT, R., PISACANE, A., HOUEN, G., RUCO, L.P. and DEJANA, E. (1992). A novel endothelial-specific membrane protein is a marker of cell-cell contacts. J. Cel/ Biol. 118: 1511-1522.

LANCRIN, C., SROCZYNSKA, P., STEPHENSON, C., ALLEN, T., KOUSKOFF, V. and LACAUD, G. (2009). The haemangioblast generates haematopoietic cells through a haemogenic endothelium stage. Nature 457: 892-895.

LE DOUARIN, N. M., HOUSSAINT, E., JOTEREAU, F. V., and BELO, M. (1975). Origin of hemopoietic stem cells in embryonic bursa of Fabricius and bone marrow studied through interspecific chimeras. Proc. Natl. Acad. Sci. USA72: 2701-2705.

LI, Z., CHEN, M.J., STACY, T. and SPECK, N.A. (2006). Runx1 function in 
hematopoiesis is required in cells that express Tek. Blood 107: 106-110.

LUCKETT WP. (1978). Origin and differentiation of the yolk sac and extraembryonic mesoderm in presomite human and rhesus monkey embryos. Am. J. Anat. 152: 59-97.

MANAIA, A., LEMARCHANDEL, V., KLAINE, M., MAX-AUDIT, I., ROMEO, P., DIETERLEN-LIEVRE, F., and GODIN, I. (2000). Lmo2 and GATA-3 associated expression in intraembryonic hemogenic sites. Development 127: 643-653.

METCALF, D. and MOORE, M. A. S. (1971). Hematopoietic cells. In North-Holland Research Monographs Frontiers of Biology-volume 24 (Eds. A. Neuberger and E. L. Tatum). North Holland Publishing, Amsterdam-London, pp. 1-550.

MIKKOLA, H.K., AND ORKIN, S.H. (2006). The journey of developing hematopoietic stem cells. Development 133: 3733-3744.

MIKKOLA, H.K., GEKAS, C., ORKIN, S.H. and DIETERLEN-LIEVRE, F. (2005). Placenta as a site for hematopoietic stem cell development. Exp. Hematol. 33: 1048-1054.

MIKKOLA, H.K., FUJIWARA, Y., SCHLAEGER, T.M., TRAVER, D. and ORKIN, S.H. (2003). Expression of CD41 marks the initiation of definitive hematopoiesis in the mouse embryo. Blood 101: 508-516.

MONVOISIN, A., ALVA, J.A., HOFMANN, J.J., ZOVEIN, A.C., LANE, T.F., and IRUELA-ARISPE, M.L. (2006). VE-cadherin-CreERT2 transgenic mouse: a model for inducible recombination in the endothelium. Dev. Dyn. 235: 34133422.

MURRAY, P.D.F. (1932). The development in vitro of blood of the early chick embryo. Proc. R. Soc. London 111: 497-521.

NISHIKAWA, S.I., NISHIKAWA, S., HIRASHIMA, M., MATSUYOSHI, N., and KODAMA, H. (1998a). Progressive lineage analysis by cell sorting and culture identifies FLK1+VE-cadherin+ cells at a diverging point of endothelial and hemopoietic lineages. Development 125: 1747-1757.

NISHIKAWA, S.I., NISHIKAWA, S., KAWAMOTO, H., YOSHIDA, H., KIZUMOTO, M., KATAOKA, H., and KATSURA, Y. (1998b). In vitro generation of lymphohematopoietic cells from endothelial cells purified from murine embryos. Immunity 8: 761-769.

NORTH, T.E., DE BRUIJN, M.F., STACY, T., TALEBIAN, L., LIND, E., ROBIN, C., BINDER, M., DZIERZAK, E., and SPECK, N.A. (2002). Runx1 expression marks long-term repopulating hematopoietic stem cells in the midgestation mouse embryo. Immunity 16: 661-672.

OBERLIN, E., TAVIAN, M., BLAZSEK, I., and PEAULT, B. (2002). Blood-forming potential of vascular endothelium in the human embryo. Development 129: 4147-4157.

PÉAULT, B., OBERLIN, E., and TAVIAN, M. (2002). Emergence of hematopoietic stem cells in the human embryo. C. R. Biol. 325: 1021-1026.

POUGET, C., POTTIN, K. and JAFFREDO, T. (2008). Sclerotomal origin of vascular smooth muscle cells and pericytes in the embryo. Dev. Biol. 315: 437447.

POUGET, C., GAUTIER, R., TEILLET, M.A., and JAFFREDO, T. (2006). Somitederived cells replace ventral aortic hemangioblasts and provide aortic smooth muscle cells of the trunk. Development 133: 1013-1022.
ROBIN, C., BOLLEROT, K., MENDES, S., HAAK, E., CRISAN, M., CERISOLI, F., LAUW, I., KAIMAKIS, P., JORNA, R., VERMEULEN, M. et al. (2009). Human placenta is a potent hematopoietic niche containing hematopoietic stem and progenitor cells throughout development. Cel/ Stem Cell 5: 385-395.

RHODES, K.E., GEKAS, C., WANG, Y., LUX, C.T., FRANCIS, C.S., CHAN, D.N., CONWAY, S., ORKIN, S.H., YODER, M.C., and MIKKOLA, H.K. (2008). The emergence of hematopoietic stem cells is initiated in the placental vasculature in the absence of circulation. Cell Stem Cell 2: 252-263.

SABIN, F.R. (1920). Studies on the origin of blood vessels and of red blood corpuscles as seen in the living blastoderm of checks during the second day of incubation. Carnegie Inst. Wash. Pub. n²72, Contrib. Embryol. 9: 214.

SORIANO, P. (1999). Generalized lacZ expression with the ROSA26 Cre reporter strain. Nat. Genet. 21: 70-71.

TAOUDI, S., GONNEAU, C., MOORE, K., SHERIDAN, J.M., BLACKBURN, C.C., TAYLOR, E. and MEDVINSKY, A. (2008). Extensive hematopoietic stem cell generation in the AGM region via maturation of VE-cadherin+CD45+ predefinitive HSCs. Cel/ Stem Cell 3: 99-108.

TAOUDI, S., MORRISON, A.M., INOUE, H., GRIBI, R., URE, J. and MEDVINSKY, A. (2005). Progressive divergence of definitive haematopoietic stem cells from the endothelial compartment does not depend on contact with the foetal liver. Development 132: 4179-4191.

TAVIAN, M., HALLAIS, M.F., and PÉAULT, B. (1999). Emergence of intraembryonic hematopoietic precursors in the pre-liver human embryo. Development 126: 793-803.

TAVIAN, M., COULOMBEL, L., LUTON, D, CLEMENTE, H.S., DIETERLENLIEVRE, F., and PEAULT, B. (1996). Aorta-associated CD34+ hematopoietic cells in the early human embryo. Blood 87: 67-72.

VODYANIK, M.A., THOMSON, J.A. and SLUKVIN, II. (2006). Leukosialin (CD43) defines hematopoietic progenitors in human embryonic stem cell differentiation cultures. Blood 108: 2095-2105.

WASTESON, P., JOHANSSON, B.R., JUKKOLA, T., BREUER, S., AKYÜREK, L.M., PARTANEN, J., and LINDAHL, P. (2008). Developmental origin of smooth muscle cells in the descending aorta in mice. Development 135: 1823-1832.

WIEGREFFE, C., CHRIST, B., HUANG, R. and SCAAL, M. (2009). Remodeling of aortic smooth muscle during avian embryonic development. Dev. Dyn. 238: 624-631.

WIEGREFFE, C., CHRIST, B., HUANG, R. and SCAAL, M. (2007). Sclerotomal origin of smooth muscle cells in the wall of the avian dorsal aorta. Dev. Dyn. 236: 2578-2585.

ZAMBIDIS, E.T., OBERLIN, E., TAVIAN, M., and PÉAULT, B. (2006). Bloodforming endothelium in human ontogeny: lessons from in utero development and embryonic stem cell culture. Trends Cardiovasc. Med. 16: 95-101.

ZOVEIN, A.C., HOFMANN, J.J., LYNCH, M., FRENCH, W.J., TURLO, K.A., YANG Y., BECKER, M.S., ZANETTA, L., DEJANA, E., GASSON, J.C., TALLQUIST, M.D., and IRUELA-ARISPE, M.L. (2008). Fate tracing reveals the endothelial origin of hematopoietic stem cells. Cell Stem Cel/ 3: 625-636. 


\section{Further Related Reading, published previously in the Int. J. Dev. Biol.}

See our recent Special Issue Placenta edited by Joan S. Hunt and Kent L. Thornburg at:

http://www.ijdb.ehu.es/web/contents.php?vol=54\&issue=2-3

Tracing the hemangioblast during embryogenesis: developmental relationships between endothelial and hematopoietic cells Thierry Jaffredo, Karine Bollerot, Daisuke Sugiyama, Rodolphe Gautier and Cécile Drevon

Int. J. Dev. Biol. (2005) 49: 269-277

Of birds and mice: hematopoietic stem cell development

Isabelle Godin and Ana Cumano

Int. J. Dev. Biol. (2005) 49: 251-257

Embryonic development of the human hematopoietic system

Manuela Tavian and Bruno Péault

Int. J. Dev. Biol. (2005) 49: 243-250

Commitment of hematopoietic stem cells in avian and mammalian embryos: an ongoing story

Françoise Dieterlen-Lièvre

Int. J. Dev. Biol. (2005) 49: 125-130.

Multilineage hematopoietic progenitor activity generated autonomously in the mouse yolk sac: analysis using angiogenesisdefective embryos

Christine Rampon and Philippe Huber

Int. J. Dev. Biol. (2003) 47: 273-280
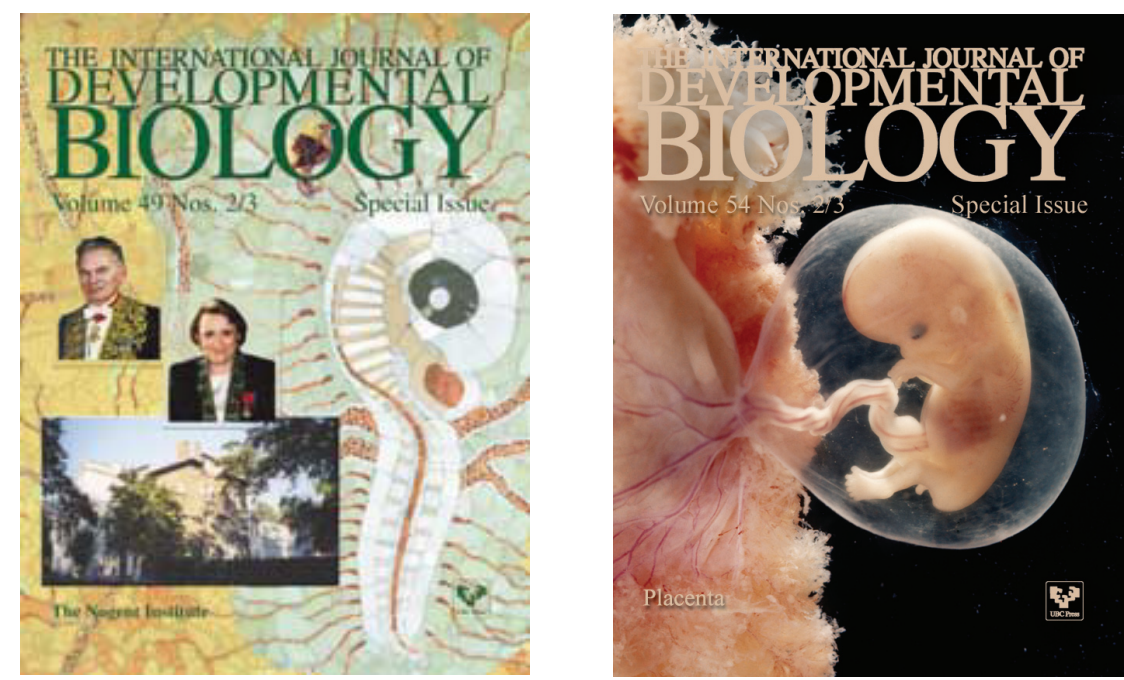

5 yr ISI Impact Factor $(2009)=3.253$

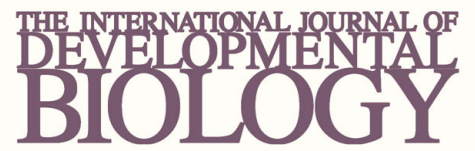

Volume 54 Nos. 6/7

Special Issue

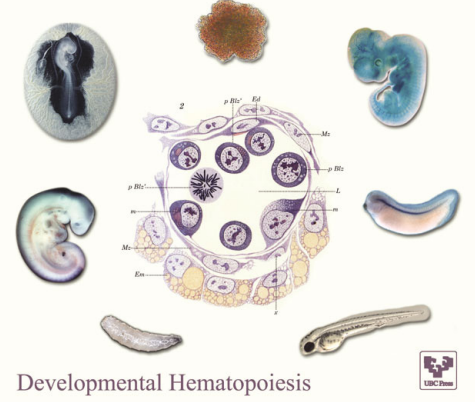

